\title{
VENTOS DE MUDANÇA NO DIREITO DO AMBIENTE A RESPONSABILIDADE CIVIL AMBIENTAL
}

\author{
VASCO PEREIRA DA SILVA*
}

\begin{abstract}
RESUMO: O artigo apresenta brevemente o contexto do direito da responsabilidade civil ambiental no sistema jurídico português. Em seguida, aponta as principais inovações da nova regulamentação da matéria no direito português através do DL. nº 147/2008.

PALAVRAS-CHAVE: Responsabilidade Civil Ambiental; Responsabilidade Objetiva; Dano Ambiental.
\end{abstract}

\begin{abstract}
The article briefly presents the context of civil environmental liability in the Portuguese legal system. Next, it points out the main innovations of the new legislation on the matter in the Portuguese Law with the LD n ${ }^{\circ}$ 147/2008.
\end{abstract}

KEYWORDS: Civil environmental liability; Objective liability; Environmental damage.

Antes de mais, seja-me permitido glosar o título desta minha intervenção, tal como me foi proposto pelos organizadores da conferência: «Ventos de Mudança no Direito do Ambiente». Trata-se de um título particularmente adequado à matéria que pretendo tratar, pelas razões que passo a expor. Suponho mesmo que é a primeira vez que aceito, sem pestanejar, um título escolhido por outrem, sem lhe dar "uma qualquer volta”, capaz de o tornar meu.

Em primeiro lugar, este título “cai-me bem”. Não só já o utilizei anteriormente, a propósito da reforma do Contencioso Administrativo («Ventos de Mudança no Contencioso Administrativo», Almedina, Coimbra, 2000), como a sua aplicação ao Direito do Ambiente, em Portugal, me parece ser particularmente adequada. Por um lado, gosto de "vento" e de "mudança", por outro lado, a combinação de ambas as coisas tem-se verificado - mas continua a ser cada vez mais necessária - no direito ambiental português.

Em segundo lugar, o título descreve bem a situação presente do Direito do Ambiente, em que "sopram ventos" e estes "trazem mudança”. Pois, existem:

a) ventos, em sentido físico, que sopram de maneira diferente do habitual, em razão das alterações climáticas. Ainda na semana passada, no Brasil, onde estive a

Artigo recebido em 7.03.2009 e aprovado para publicação pelo Conselho Editorial em 23.06.2009.

* Professor da Faculdade de Direito da Universidade de Lisboa e da Universidade Católica Portuguesa. O presente texto corresponde à versão escrita da intervenção realizada no Colóquio sobre "As Novidades Legislativas no Direito do Ambiente», organizado pelo Instituto de Ciências Jurídico-Políticas, que teve lugar na Faculdade de Direito da Universidade de Lisboa, no dia 14 de Novembro de 2008. 
fazer uma palestra, toda a gente comentava o inesperado vento, surgido de repente, o que dava também origem a pequenas excursões familiares, com os pais a passear os filhos pela mão, a fim de lhes mostrar a força da Natureza. Ventos, marés, frio, calor - hoje em dia, parece que todos os elementos naturais surgem "fora" de tempo ou de espaço, tornando evidentes aos olhos de todos a questão das alterações climáticas e colocando novos desafios ao Direito do Ambiente;

b) ventos jurídicos, que correm da Europa, e que obrigam a considerar seriamente os fenómenos ambientais. Pois, em boa verdade, decisiva tem sido a importância do Direito Europeu do Ambiente, tanto para a criação de um corpo autónomo de regras comuns como para a aproximação do tratamento das questões ambientais nos diferentes países da União. Basta referir que considerável parte dos diplomas legislativos portugueses em matéria ambiental têm origem europeia;

c) ventos portugueses, que significam que as questões ambientais começam a ser "levadas a sério", também entre nós. Veja-se a produção legislativa mais recente (que, de resto, está na origem deste colóquio), desde a lei-quadro das contra-ordenações ambientais, às alterações dos regimes jurídicos do licenciamento ou da REN, ou à nova lei de responsabilidade civil ambiental que motiva estas minhas breves reflexões (DL n ${ }^{\circ}$ 147/2008, de 29 de Junho) ${ }^{1}$.

Até agora, a responsabilidade civil ambiental, entre nós, podia ser caracterizada pela "falta de "unidade"», dando origem «a uma situação de verdadeira "manta de retalhos" de soluções jurídicas, a uma espécie de "labirinto" jurídico, que faria as delícias do escritor Jorge Luís Borges» ${ }^{2}$. Pois, conforme anteriormente escrevi, «se o recurso aos direitos fundamentais permite reconduzir os problemas jurídicos do ambiente, em geral, a uma unidade de referência normativa e de construção dogmática, possibilitando o seu tratamento em termos de "sistema”, já o problema da responsabilidade civil no domínio do ambiente, sobretudo se se tiver presente o seu tratamento legislativo parece ser antes marcado pela ideia de fragmentação. E isto a dois níveis:

a) do regime jurídico, em que se verifica um tratamento diferenciado da responsabilidade civil da Administração e dos particulares no domínio do ambiente, para além da própria regulação da responsabilidade administrativa não ser uniforme (ora submetida a regras específicas, ora subordinada às mesmas regras que os privados). Mais ainda: no domínio da responsabilidade civil ambiental não apenas se verifica uma multiplicidade de fontes de direito (Constituição; D.L. n. ${ }^{\circ}$ 48051, Lei de Bases do Ambiente, Código Civil, Lei da Acção Popular), como parece ter existido uma regulação parcelar e fragmentada da matéria, dado o carácter "estanque” dos sucessivos tratamentos legislativos, que toma difícil caracterizar o instituto da responsabilidade civil no domínio ambiental;

\footnotetext{
${ }^{1}$ A nova lei da responsabilidade civil ambiental resulta da transposição da Directiva $n^{\circ}$ 2004/35/CE do Parlamento Europeu e do Conselho, de 21 de Outubro (com as alterações introduzidas pela Directiva $n^{\circ}$ 2006/21/CE).

${ }^{2}$ VASCO PEREIRA DA SILVA, «Verde Cor de Direito - Lições de Direito do Ambiente», Almedina, Coimbra, 2003, p. 251.
} 
b) do tribunal competente, uma vez que as questões da responsabilidade civil no domínio do ambiente tanto são da competência da jurisdição comum como da jurisdição administrativa, com os inerentes problemas de conflito de jurisdições. Dualidade de jurisdições que se toma ainda mais indesejável no domínio da responsabilidade administrativa em matéria de ambiente, causando "problemas insolúveis” de determinação do tribunal competente para a reparação de danos causados pela Administração pública. Dir-se-ia, ironizando, que no que respeita à responsabilidade administrativa em matéria de ambiente se verifica uma "duplicação" dos problemas decorrentes da dualidade de jurisdições» ${ }^{3}$.

Daí a afirmação da necessidade imperiosa de uma específica e autónoma lei da responsabilidade civil ambiental, capaz de resolver tanto os problemas decorrentes da natureza dispersa, confusa e contraditória dos (múltiplos) regimes jurídicos (substantivos) aplicáveis neste domínio; como também da indesejável dualidade de jurisdições em matéria de responsabilidade civil ambiental ${ }^{4}$ (mesmo considerando que se verificou uma clarificação dos critérios de delimitação do âmbito das jurisdições, assim como se produziram sensíveis “melhorias de sistema”, em consequência da recente reforma do Contencioso Administrativo) ${ }^{5}$.

Esta exigência de uma autónoma lei de responsabilidade civil ambiental justifica-se tanto em razão da respectiva natureza multifuncional, implicando a consideração simultânea, entre outras, das dimensões preventiva, repressiva, compensatória e reconstitutiva, como em razão das especificidades da responsabilidade civil ambiental ${ }^{6}$. De entre as especificidades da responsabilidade civil ambiental, refira-se:

a) a necessidade de valorização tanto da responsabilidade civil subjectiva como da objectiva (pelo risco, por actos lícitos ou pelo prejuízo). Posto que, neste domínio, a existência de um dano ao ambiente tanto pode ser provocada por factos ilícitos como corresponder ao risco do funcionamento de uma empresa ou de exercício de uma actividade económica, da mesma maneira como pode ainda corresponder a actuações lícitas ou autorizadas mas, não obstante, nocivas;

b) a necessidade de adoptar (na responsabilidade civil subjectiva) uma noção objectivada de culpa. Na medida em que tão ou mais importante do que proceder apenas a juízos de natureza ética ou de reprovabilidade social, é antes a possibilidade de imputação de condutas humanas danosas do ambiente ao respectivo autor;

c) a necessidade de distinguir o dano subjectivo (também chamado dano ambiental), que é susceptível de individualização em face dos titulares de direitos

${ }^{3}$ VASCO PEREIRA DA SILVA, «Verde C. de D. - L. de D. do A.», Almedina, pp. 250 e 251.

${ }^{4}$ Vide VASCO PEREIRA DA SILVA, «Verde C. de D. - L. de D. do A.», Almedina, pp. 248 e ss; «Ensinar Verde a Direito - Estudo de Metodologia do Ensino do Direito do Ambiente (em “Ambiente de Bolonha”)», Almedina, Coimbra, 2006, páginas 187 e seguintes.

${ }^{5}$ Sobre as consequências da reforma do Contencioso Administrativo para a tutela jurisdicional do ambiente, vide MÁRIO AROSO DE ALMEIDA, «Tutela Jurisdicional em Matéria Ambiental», in «Estudos de Direito do Ambiente», UCP, Porto, 2003, páginas 77 e seguintes, MARIA JOANA FÉRIA COLAÇO, «A Tutela Jurisdicional do Ambiente», in «Revista Jurídica do Urbanismo e do Ambiente», nos. 27 /28 (Jan. / Dez.), 2007, páginas 89 e seguintes.

${ }^{6}$ Vide VASCO PEREIRA DA SILVA, «Verde C. de D. - L. de D. do A.», Almedina, pp. 248 e ss; «Ensinar V. a D. - E. de M. do E. do D. do A. (em “A. de B.”)», cit., pp. 187 e ss.. 
subjectivos, do dano objectivo (também chamado dano ecológico ${ }^{7}$ ), que é produzido relativamente a toda a comunidade;

d) a necessidade de ter em atenção que os danos ao ambiente apresentam em regra uma multiplicidade de causas, normalmente em concurso, o que obriga a adoptar uma teoria da causalidade "ambientalmente adequada" raramente é possível identificar uma única causa geradora de um dano ambiental, verificando-se antes, em regra, um "concurso" de causas», da mesma maneira como «os factos causadores da lesão ambiental tanto podem agir isoladamente, como conjugados, ou até em colisão com outros factos; para além de poderem ainda depender de circunstâncias "externas", como as condições meteorológicas do momento, ou a propagação através das águas (v.g. tenha-se presente o caso das florestas atingidas por chuvas ácidas, ou dos incêndios na Indonésia, potenciados por realidades climatéricas - como o "El Niño - situadas a grande distância)»" . Daí a necessidade de estabelecimento de "presunções de causalidade", como sucede no «direito alemão, que consagra uma cláusula geral de "presunção de causalidade" ("Ursachenvermutung” - vide o parágrafo $6^{\circ}$ da "Umwelthaftungsgesetz"), segundo a qual, "sempre que uma empresa estiver, de acordo com as circunstâncias do caso concreto, em condições de provocar os danos verificados, presume-se que tais danos foram por ela causados" ${ }^{10}$; ou em alternativa a «consideração da necessidade «de uma certa flexibilidade ("souplesse")» na aplicação das regras da causalidade, designadamente recorrendo às «regras da probabilidade» (GILLES MARTIN $\left.{ }^{11}\right)^{12}$. Ora, quer a "flexibilização" das regras de causalidade quer a adopção de "presunções de causalidade", «implica a atribuição de amplos poderes de decisão ao juiz, a quem compete verificar a aptidão dos factos para a produção dos danos, em razão de circunstâncias como a da situação

\footnotetext{
${ }^{7}$ Vide JOSÉ CUNHAL SENDIM, «Responsabilidade Civil por Danos Ecológicos. Da Reparação do Dano Através de Restauração Natural», Coimbra Editora, Coimbra, 1998.

${ }^{8}$ Sobre os problemas da causalidade no Direito do Ambiente vide ANA PERESTRELO DE OLIVEIRA, «Causalidade e Imputação na Responsabilidade Civil Ambiental», Almedina, Coimbra, 2007.

${ }^{9}$ VASCO PEREIRA DA SILVA, «Verde C. de D. - L. de D. do A.», Almedina, p. 261.

${ }^{10}$ Sobre a presunção de causalidade na responsabilidade civil ambiental assim como a tutela judicial do direito do ambiente, no direito alemão, vide HOPPE / BECKMANN / KAUCH, «Umweltrecht», $2^{\mathrm{a}}$ edição, Beck, München, 2000, páginas 305 e seguintes; JOACHIM WOLF, «Umweltrecht», Beck, München, 2002, páginas 110 e seguintes; SPARWASSER / ENGEL / VOSSKUHLE, «Umweltrecht - Grundzüge des öffentlichen Umweltschutzrechts», $5^{a}$ edição, Müller, Heidelberg, 2003, páginas 235 e seguintes; SCHMIDT / KAHL, «Umweltrecht», $7^{\mathrm{a}}$ edição, Beck, München, 2006, páginas 33 e seguintes, PETERCHRISTOPH STORM, «Umweltrecht - Einführung», 8. edição, Erich Schmidt Verlag, Berlin, 2006, páginas 106 e seguintes; HANS-JOACHIM KOCH, «Umwelrecht», 2a. edição, Carl Heymanns Verlag, köln, Berlin, München, 2007.

${ }^{11}$ GiLlES MARTiN, «Responsabilité Civile et Protection de L' Environment - Introduction», in «Ambiente - Textos», C.E.J., Lisboa, 1994, página 400.

12 Sobre a flexibilização da causalidade na responsabilidade civil ambiental, no direito francês, vide PHILIPPE GUILLOT, «Droit de l' Environnement», Ellipse, Paris, 1998, páginas 198 e seguintes; AGATHE VAN LANG, «Droit de l' Environnement», PUF, Paris, 2002, páginas 220 e seguintes; MICHEL PRIEUR, «Droit de l' Environnement», 5a edição, Dalloz, Paris, 2004, páginas 915 e seguintes; VÉRONIQUE INSERGUT-BRISSET, Droit de l' Environnement», Presses Universitaires de Rennes, Rennes, 2005, páginas 271 e seguintes; CATHERINE ROCHE, «Droit de l’ Environnement», 2ª edição, Gualino, Paris, 2006.
} 
da empresa, a do seu modo de funcionamento, a das condições meteorológicas existentes, entre outros critérios» ${ }^{13}$.

Uma tal inadequação para lidar com a responsabilidade ambiental tornou-se ainda mais evidente com a necessidade de compatibilizar a legislação nacional com o Direito Europeu ${ }^{14}$ - em especial, a Directiva sobre responsabilidade civil ambiental (2004/35/CE), que se tornou vigente no nosso ordenamento, mesmo se só agora (tardiamente) se procedeu à respectiva transposição.

Em primeiro lugar, a directiva comunitária consagra um "novo paradigma” da responsabilidade civil ambiental, que conjuga prevenção e reparação, responsabilizando de forma directa as autoridades públicas pelos danos ambientais verificados (independentemente da possibilidade destas virem, depois, a responsabilizar os sujeitos - privados ou públicos - causadores do dano). Cria-se, portanto, um regime de responsabilidade civil que é, em primeira linha, de natureza pública, virado para a prevenção de lesões ambientais, mas que permite igualmente a reparação, tanto dos particulares directamente lesados, como da comunidade no seu todo, pela verificação de danos ambientais.

Em segundo lugar, a directiva trouxe importantes inovações ao regime jurídico da responsabilidade ambiental, nomeadamente:

a) a (referida) consagração de uma responsabilidade pública, de primeira linha, que é independente da posterior responsabilização do sujeito (público ou privado) causador do dano;

b) a adopção de uma noção ampla e objectiva de "dano ambiental” (que põe em causa a distinção doutrinária entre “dano ambiental” e “dano ecológico”, alargando o primeiro de modo a abarcar também o segundo);

c) a adopção de uma noção ampla de responsabilidade, envolvendo tanto o “antes” como o “depois”, e que obriga à conjugação de acções de prevenção com acções de reparação dos danos ambientais;

a preferência pela "reconstituição natural"15 em vez da simples "reparação" dos danos, obrigando à tomada de medidas activas de protecção do ambiente;

d) o estabelecimento de deveres de colaboração entre os Estados membros em matéria de prevenção e de reparação.

Em terceiro lugar, as discrepâncias entre as fontes de origem nacional e europeia eram de tal ordem que obrigavam à reconstrução integral do regime da responsabilidade ambiental. Assim, a necessidade de “dar cumprimento” ao Direito

${ }^{13}$ VASCO PEREIRA DA SILVA, «Verde C. de D. - L. de D. do A.», Almedina, pp. 261 e 262.

14 Sobre o Direito Europeu da Responsabilidade Civil ambiental, vide LUDWIG KRÄMER, «EC Environmental Law», 5a edição, Sweet \& Maxwell, London, 2003; CARMEN PLAZA MARTÍN, «Derecho Ambiental de la Unión Europea», Tirant lo Blanch, Valência, 2005; MARTIN HEIDEMANNROBINSON, «Enforcement of European Union Environmental Law - Legal Issues and Challenges», Routledge - Cavendish, London - New York, 2007.

${ }^{15}$ Sobre a importância da reconstituição natural no Direito do Ambiente, vide JOSÉ CUNHAL SENDIM, «Responsabilidade C. por D. E.. Da R. do D. A. de R. N.», Coimbra Editora, cit., pp. 153 e ss.; JESÚS CONDE ANTEQUERA, «El Deber Jurídico de Restauración Ambiental», Comares, Granada, 2004. 
Europeu, entre nós, surgia como a "oportunidade ideal”, não apenas para transposição da Directiva, mas também para regular de forma sistemática e integrada, através de lei própria, todo o "universo jurídico" da responsabilidade civil em matéria de ambiente.

É, por isso, de saudar o surgimento do D.L. n ${ }^{\circ}$ 147/2008, de 29 de Julho, que estabelece o novo regime (integrado) da responsabilidade civil ambiental. E como "é dia de festa”, pelo facto do legislador ter atendido aos apelos da doutrina e ter-se decidido a consagrar um regime próprio para a responsabilidade ambiental, deixemos, por ora, de lado os aspectos menos bons do diploma jurídico (que, infelizmente, também os tem), e louvemos os seus aspectos positivos (que procuram dar resposta a grande parte dos problemas anteriormente referenciados).

Assim, resolve-se em primeiro lugar a questão da falta de unidade legislativa, mediante a criação de um regime jurídico próprio e específico da responsabilidade civil ambiental. E aqui só é de lamentar a auto-contenção ou "timidez" legislativa que, em razão de lacunas ou de deficiência legislativa, obriga a invocar - ainda que a título meramente subsidiário - o regime regra da responsabilidade civil. Sendo certo, no entanto, que este novo regime apresenta, entre outras, a vantagem da perda de relevância da distinção entre actos ditos de gestão pública e de gestão privada neste domínio - mesmo se são justificadas as dúvidas quanto à sua manutenção, ou não, no diploma geral acerca da responsabilidade civil pública (D.L. $n^{\circ}$ 67/ 2007, de 31 de

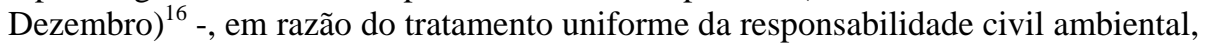
independentemente da natureza (pública ou privada) do autor do dano.

Em segundo lugar, ao conferir natureza jurídico-pública à relação de responsabilidade civil ambiental, o legislador faz do contencioso administrativo o foro privilegiado para a resolução de litígios em matéria ambiental. Daqui resultando (pelo menos) uma tendencial unidade jurisdicional em matéria de responsabilidade ambiental, uma vez que (como estabelece a alínea l, do $\mathrm{n}^{\circ} 1$ do art. $4^{\circ}$ do ETAF - para além das alíneas g, h, e i, do mesmo artigo) compete aos tribunais administrativos e fiscais «promover a prevenção, cessação e reparação de violações a valores e bens constitucionalmente protegidos (...) no domínio do ambiente». Desta forma, "o grosso" das questões da responsabilidade ambiental compete ao contencioso administrativo, em resultado da publicização do respectivo regime jurídico, bem patente, de resto, nos poderes de intervenção das autoridades administrativas no quadro das relações multilaterais de direito do ambiente - v.g. medidas de prevenção (art. 14º), medidas de reparação (art. $15^{\circ}$ ), determinação das medidas de reparação (art. $16^{\circ}$ ), pedido de intervenção dos particulares (art. 18º Também aqui, só é pena que o legislador não tenha consagrado expressamente um "único" tribunal competente nesta matéria, embora "quase" que o tenha feito (uma vez que "de fora" do contencioso administrativo ficarão apenas as relações puramente privadas, relativamente às quais não se coloque qualquer possibilidade de controlo, fiscalização ou de polícia, por

\footnotetext{
${ }^{16}$ Sem pretender agora discutir a questão, refira-se, no entanto, a fórmula ambígua utilizada pela Lei no 67/2007, de 31 de Dezembro (Regime da Responsabilidade Civil Extracontratual do Estado e Demais Entidades Públicas), que, no seu artigo $1^{\circ}, n^{\circ} 2$, se refere tanto às «acções e omissões adoptadas no exercício de prerrogativas de poder público» (permitindo assim o "ressuscitar” da “defunta” distinção gestão pública / gestão privada) como às «reguladas por disposições ou princípios de direito administrativo».
} 
parte das autoridades administrativas - o que será uma hipótese muito rara), sendo agora de esperar também o futuro surgimento de tribunais especializados em matéria ambiental no domínio do contencioso administrativo (vide o art. $9^{\circ}, n^{\circ} 4$, do ETAF).

Em terceiro lugar, as soluções adoptadas em matéria de regime jurídico da responsabilidade ambiental procuram dar resposta às especificidades existentes neste domínio. Assim, grande parte dos problemas referidos no breve diagnóstico, antes efectuado, encontra parcialmente solução no D.L. n 147/2008, de 29 de Julho, designadamente:

a) a regulação da responsabilidade civil ambiental tanto objectiva (art. $\left.7^{\circ}\right)^{17}$ como subjectiva (art. $\left.8^{\circ}\right)^{18}$. E isto tanto no respeitante a danos efectivamente provocados, como em relação a ameaças de lesão (art. $12^{\circ}$, responsabilidade objectiva ${ }^{19}$, e art. $13^{\circ}$, responsabilidade subjectiva ${ }^{20}$ ). Estamos, pois, perante um regime jurídico que engloba assim tanto as categorias clássicas da responsabilidade por factos ilícitos (responsabilidade subjectiva), como pelo risco e pelo prejuízo ou acto lícito (responsabilidade objectiva);

b) a busca de uma noção objectivada de culpa na responsabilidade civil subjectiva, mesmo se a lei não consagra uma disposição geral sobre este problema (o que, a meu ver, representa uma lacuna maior ao nível do regime jurídico). Contudo, existem afloramentos dessa ideia, designadamente no art. $3^{\circ}$, acerca da responsabilidade das pessoas colectivas, que consagra a responsabilidade solidária dos respectivos directores, gerentes ou administradores, ${ }^{21}$ e no art. $4^{\circ}$, que se ocupa da comparticipação, e em que se estabelece a responsabilidade solidária quando o facto danoso seja imputado a mais do que um autor $\left(n^{\circ} .1\right)$, e se consagra, em caso de dúvida acerca do grau de participação dos sujeitos, uma presunção de repartição da responsabilidade em partes iguais $\left(\mathrm{n}^{\mathrm{o}} 2\right)^{22}$;

${ }^{17}$ Segundo o art. $7^{\circ}$ (Responsabilidade objectiva), do D.L. $\mathrm{n}^{\circ}$ 147/2008, de 29 de Julho, «quem, em virtude do exercício de uma actividade económica enumerada no anexo III (...), ofender direitos ou interesses alheios por via da lesão de um qualquer componente ambiental é obrigado a reparar os danos resultantes desta ofensa, independentemente da existência de culpa ou dolo».

${ }^{18}$ Nos termos do art. $8^{\circ}$ (Responsabilidade subjectiva), do D.L. $n^{\circ} 147 / 2008$, de 29 de Julho, «quem, com dolo ou mera culpa, ofender direitos ou interesses alheios por via da lesão de um componente ambiental fica obrigado a reparar os danos resultantes dessa ofensa».

${ }^{19}$ De acordo com o art. $12^{\circ}$ (Responsabilidade objectiva), $n^{\circ} 1$, do D.L. ${ }^{\circ}$ 147/2008, de 29 de Julho, «o operador que, independentemente da existência de dolo ou culpa, causar um dano ambiental em virtude do exercício de qualquer das actividades ocupacionais referidas no anexo III (...) ou uma ameaça iminente daqueles danos em resultado dessas actividades, é responsável pela adopção de medidas de prevenção e reparação dos danos ou ameaças causados (...).

${ }^{20}$ Conforme estabelece o art. $13^{\circ}$ (Responsabilidade subjectiva), ${ }^{\circ} 1$, do D.L. $\mathrm{n}^{\circ}$ 147/2008, de 29 de Julho, o operador que, com dolo ou negligência, causar um dano ambiental em virtude do exercício de qualquer actividade ocupacional distinta das enumeradas no anexo III (...) ou uma ameaça iminente daqueles danos em resultado dessas actividades, é responsável pela adopção de medidas de prevenção e reparação dos danos ou ameaças causados (...)».

${ }^{21}$ Segundo o art. $3^{\circ}$ (Responsabilidade das pessoas colectivas), $n^{\circ} 1$, do D.L. ${ }^{\circ} 147 / 2008$, de 29 de Julho, «quando a actividade lesiva seja imputável a pessoa colectiva, as obrigações previstas no presente decretolei incidem solidariamente sobre os respectivos directores, gerentes ou administradores». Acrescentando o $\mathrm{n}^{\circ} 2$, do referido artigo, que «no caso de o operador ser uma sociedade comercial que esteja em relação de grupo ou de domínio, a responsabilidade ambiental estende-se à sociedade-mãe ou à sociedade dominante quando exista utilização abusiva da personalidade jurídica ou fraude à lei».

${ }^{22}$ Nos termos do art. $4^{\circ}$ (Comparticipação), $\mathrm{n}^{\circ} 1$, do D.L. $\mathrm{n}^{\circ}$ 147/2008, de 29 de Julho, «se a responsabilidade 
c) a consagração de uma noção ampla de dano ambiental, abrangendo tanto os danos subjectivos como os objectivos. O que tem como consequência pôr em causa a anterior distinção entre dano ambiental e dano ecológico (vide o art. $11^{\circ}, \mathrm{n}^{\mathrm{o}} 1$, alínea $\mathrm{e}^{23}$ ), que perde "utilidade prática”, uma vez que tanto a prevenção como a reparação devem dizer respeito tanto ao dano subjectivo como objectivo;

d) a adopção de uma teoria da “causalidade ambientalmente adequada”, que supera a rigidez do paradigma tradicional da "causalidade adequada" (art. 50). Pois, agora, o nexo de causalidade em matéria de responsabilidade ambiental passa a assentar num "critério de verosimilhança e de probabilidade", que deve tomar em consideração as "circunstâncias do caso concreto", o "grau de risco e de perigo e a normalidade da acção lesiva”, assim como a "possibilidade de prova científica do percurso causal e o cumprimento, ou não, de deveres de protecção" 24 . Assim, se me permitem a ironia (um pouco negra) do exemplo (que costuma ter bastante êxito junto dos meus estudantes), para determinar a responsabilidade civil pela "doença das vacas loucas”, que vitimou, hoje, John Smith, já não é preciso fazer a "prova diabólica” de descobrir a vaquinha Daisy, infectada pela moléstia, e cujos bifes ele teria porventura comido há cerca de dois anos, bastando apenas provar que ele se alimentava habitualmente de carne e que existem provas científicas de que a carne das vacas doentes pode provocar tal doença nos humanos que a ingerem ${ }^{25}$.

Por tudo isto, e chegada a hora de concluir, pode-se afirmar que "sopram ventos no Direito do Ambiente: são bons ventos e trazem consigo mudança!...”

recair sobre várias pessoas, todas respondem solidariamente pelos danos, mesmo que haja culpa de alguma ou algumas, sem prejuízo do correlativo direito de regresso que possam exercer reciprocamente». Acrescentando-se, no $\mathrm{n}^{\circ}$ 2, que «quando não seja possível individualizar o grau de participação de cada um dos responsáveis, presume-se a sua responsabilidade em partes iguais. Estabelecendo ainda o $\mathrm{n}^{\circ} 3$, que «quando a responsabilidade recais sobre várias pessoas responsáveis a título subjectivo (...), o direito de regresso entre si é exercido na medida das respectivas culpas e das consequências que delas advieram, presumindo-se iguais as culpas dos responsáveis».

${ }^{23} \mathrm{O}$ artigo $11^{\circ} \mathrm{n}^{\circ} 1$, alínea e), do D.L. $\mathrm{n}^{\circ} 147 / 2008$, de 29 de Julho, entende como «danos ambientais»: os «danos causados às espécies e habitats protegidos» (i), os «danos causados à água» (ii) e os «danos causados ao solo» (iii). Sendo todos eles caracterizados, nos termos mais amplos possíveis, como «quaisquer danos com efeitos significativos adversos» para o respectivo elemento (ou expressão similar). ${ }^{24} \mathrm{O}$ artigo $5^{\circ}$ (nexo de causalidade), do D.L. n ${ }^{\circ} 147 / 2008$, de 29 de Julho), estabelece que «a apreciação da prova do nexo de causalidade assenta num critério de verosimilhança e de probabilidade de o facto danoso ser apto a produzir a lesão verificada, tendo em conta as circunstâncias do caso concreto e considerando, em especial, o grau de risco e de perigo e a normalidade da acção lesiva, a possibilidade de prova científica do percurso causal e o cumprimento, ou não, de deveres de protecção».

${ }^{25}$ Conforme se escreveu anteriormente, tudo isto resulta da alteração da "dieta alimentar”, que fez com que a vaca, que era um pacífico herbívoro, fosse «transformada num feroz carnívoro - ainda para mais canibal -, ao passar a ser alimentada por rações animais - que possuem uma componente de carne de outros animais e mesmo de carne de outras vacas -». Daí que, «mesmo na ausência de "provas científicas irrefutáveis” (seja lá o que isso for) de que a doença das vacas seja exclusivamente provocada pelas rações, é razoável considerar, em razão das circunstâncias de tempo e de lugar em que se verificou o surgimento e a propagação da doença, que existe uma relação causal entre ambas, justificando-se assim que, em nome do princípio da prevenção, sejam proibidas as rações animais na alimentação do gado (como, de resto, já hoje vigora ao nível europeu)» (VASCO PEREIRA DA SILVA, «Verde C. de D. - L. de D. do A.», cit., p. 72). 